\section{EAGER TO DEMONSTRATE CUTTING-EDGE PRODUCTS}

Discover why CS R4 Clinical+ from Carestream Dental is the practice management software of choice for dental professionals at this year's British Dental Conference and Exhibition.

Visit the friendly and knowledgeable team on the Carestream Dental stand who will be available throughout the event. Eager to take your questions and offer demonstrations, the team will explain the time- and cost-saving benefits of cutting-edge products including:

- CS R4 Clinical+ practice management software: for complete integration and total control.

CS R4 becomes the hub of your business

- AutoPost: takes care of all your paper correspondence at the click of a button

- CS 8100: OPG unit for faster and more powerful panoramic performance

- CS 7600: swift, secure and smart X-ray scanning.

For more information, contact Carestream Dental on 0800169 9692 or visit www.carestreamdental.co.uk.

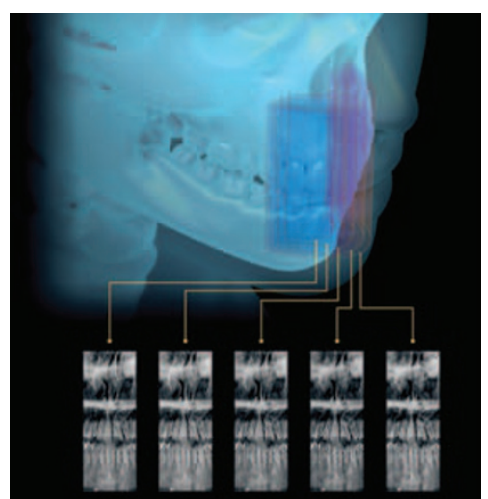

\title{
ACHIEVE A WHOLE MOUTH CLEAN
}

Delegates at the 2013 British Conference and Exhibition are invited to see for themselves the brand new Waterpik Complete Care system. A new level in

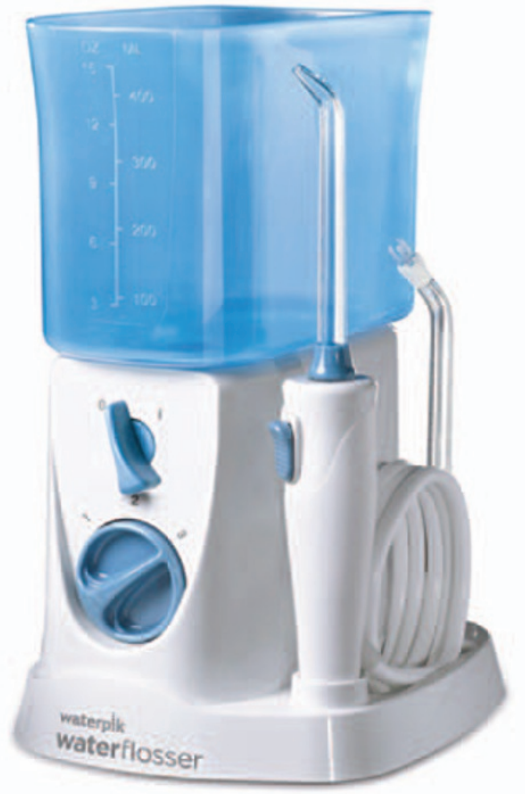

water flossing technology, Complete Care is the easiest, quickest and most convenient way for patients to achieve a whole mouth clean.

Combining a Waterpik Water Flosser and Sensonic Professional Plus Sonic Toothbrush in one compact unit, Waterpik Complete Care is suitable for the majority of patients - even those with orthodontic braces and implants.

Peerless for its clinically proven superiority, the Waterpik Water Flosser removes up to 99.9\% of plaque biofilm from treated areas in just three seconds. It can also remove plaque from the subgingival and interproximal areas that cannot be reached by a toothbrush. Meanwhile the Sensonic Professional Plus has up to 25\% faster bristle speed and 29\% better plaque removal than other sonic toothbrushes on the market.

Compliance is key to patients' self care. When you recommend Complete Care, you're introducing patients to a scientifically backed product that is highly user-friendly. Go to the Waterpik stand and discover the clinical research behind the innovation. www.waterpik.co.uk

\section{CLINICAL EXCELLENCE THROUGH EDUCATION}

The British Academy of Cosmetic Dentistry (BACD) will be appearing at this year's British Dental Conference and Exhibition, and will be on hand to provide guidance and support on all areas pertaining to cosmetic dentistry in the UK.

With a core value of 'clinical excellence through education', the BACD strives to share knowledge and expertise across the profession, while dispelling many of the myths that still surround cosmetic dentistry to this day.

One of the cornerstones of the BACD's success is its strong focus on education, as the BACD prides itself on offering outstanding educational opportunities to members, as well as a structured 'career pathway' for members keen to enhance their skills in providing cosmetic treatments. For many members, regional meetings are an absolutely essential part of their BACD membership, and provide a great way to learn practical new skills while also networking with colleagues in the local area. The BACD also hosts an Annual Conference, which this year will be held in London, and will be a particularly special occasion as the event marks the Academy's 10th anniversary.

To learn more about how BACD membership can benefit your career, visit the BACD at stand J13! Or call 0207612 4166,emailsuzy@bacd.com or visit www.bacd.com.

\section{THERE FOR YOU DURING A CRISIS}

Visit the BDA Benevolent Fund's stand at the British Dental Conference and Exhibition to find out how the dentists' charity is there to help you and your colleagues in times of crisis. The team will be available on stand L03.

Come to say hello and the Benevolent Fund will tell you all about the 'Be Active for the Ben Fund' campaign.
Without support from the profession, it would be impossible for the Fund to help dentists and their families who are struggling.

You are also invited to the BDA Charity Auction on 25 April at the British Dental Conference and Exhibition Drinks Reception. Bid for items given by major spon- sors of the conference, and luxury gifts and experiences. All proceeds will be shared between the Benevolent Fund and Bridge2Aid.

For more information call 020 7486 4994, email dentistshelp@ btconnect.com or visit www.bdabenevolentfund.org.uk. All enquiries are considered in confidence. 